\title{
Neonatal Hyperthyroidism Impairs Epinephrine- Provoked Secretion of Nerve Growth Factor and Epidermal Growth Factor in Mouse Saliva
}

\author{
J. LAKSHMANAN AND CARLISLE P. LANDEL
}

Growth Factor Laboratory, Center for Neurologic Study, San Diego, California 92121

\begin{abstract}
We examined long-term effects of neonatal hyperthyroidism on salivary secretions of nerve growth factor and epidermal growth factor in male and female mice at the age of 31 days. Hyperthyroidism was induced by thyroxine (T4) injections ( $0.4 \mu \mathrm{g} / \mathrm{g}$ body weight/day) during days $0-6$. Littermate control mice were treated with vehicle. T4 treatment did not alter the amounts of protein secreted into saliva but hormone administration induced alteration in the types of protein secreted. T4 treatment decreased the contents of both nerve growth factor and epidermal growth factor secreted into the saliva. A Sephadex G-200 column chromatographic profile revealed the presence of two distinct nerve growth factor immunoreactive peaks, while epidermal growth factor immunoreactivity predominantly eluted as a single low molecular weight form. T4 treatment did not alter the molecular nature of their secretion, but the treatment decreased their contents. These results indicate an impairment in salivary secretion of nerve growth factor and epidermal growth factor long after T4 treatment has been discontinued. (Pediatr Res 20: $587-592,1986$ )
\end{abstract}

\section{Abbreviations}

NGF, nerve growth factor

EGF, epidermal growth factor

SMG, submandibular gland

T4, thyroxine

T3, triiodothyronine

RIA, radioimmunoassay

SDS, sodium dodecyl sulfate

PAGE, polyacrylamide gel electrophoresis

Mouse SMG contains NGF, EGF, and several other biologically active substances in extraordinarily high concentrations. Both NGF and EGF are synthesized and stored in the secretory granules of the convoluted granular tubules of the SMG. The contents of the granules, including both NGF and EGF, are secreted into saliva in response to various neurotransmitter stimuli (reviewed in Ref. 1). The size and the granularity of the SMG are under multihormonal control (2-4). However, it is not yet clear whether hormones regulate the release mechanisms mediated by various neurotransmitter stimuli. Recent studies have revealed a critical role for thyroid hormones in the regulation of the glandular contents of NGF and EGF (5-7). Therefore, in the

Received November 18, 1985; accepted February 11, 1986

Correspondence should be addressed to J. Lakshmanan, Growth Factor Laboratory, Center for Neurologic Study, 11211 Sorrento Valley Road, Suite H, San Diego, CA 92121

This work was supported by NIH Grant NS-17431. present study we have investigated the effects of neonatal hyperthyroidism on the secretions of SMG-NGF and EGF in epinephrine-provoked saliva. The results of these studies are reported herein.

\section{MATERIALS AND METHODS}

Animal studies. Time-dated pregnant Swiss Webster mice were purchased from Simonsen Laboratories (Gilroy, CA). They were housed in a vivarium and were given food and water ad libitum. Pups born within $16 \mathrm{~h}$ were pooled and randomly distributed, eight pups per dam. Each litter was divided into two groups. Four pups in each litter were given subcutaneous thyroxine $(0.4$ $\mu \mathrm{g} / \mathrm{g}$ body weight/day) injections in a $5 \mu \mathrm{l}$ volume of alkaline saline. The remaining animals were given a similar volume of alkaline saline. Injections were made from birth (day 0 ) through day 6. Animals were inspected daily for maternal care and were changed to new cages. On day 21 , the young ones were isolated from mother and maintained four per cage. Male and female animals were housed in separate cages.

On day 31 mice were anaesthetized with intraperitoneal injection of sodium pentobarbitol $(60 \mathrm{mg} / \mathrm{kg}$ body weight $)$. Salivation was induced by the intraperitoneal injection of epinephrine (3$6 \mathrm{mg} / \mathrm{kg}$ ). We chose epinephrine, the most potent autonomic stimulant, since adrenergic innervation plays a major role in the protein secretory mechanism in SMG (8). Animals showed individual variations in their ability to secrete saliva in response to epinephrine injection. Routinely, mice were given a single injection of epinephrine $(3 \mathrm{mg} / \mathrm{kg})$. If saliva secretion did not occur within $10 \mathrm{~min}$ a second injection of epinephrine was given. In control animals, saliva secretion occurred most often immediately after the first injection, T4-treated mice often required a second injection. In all animals, saliva collected during the first $30 \mathrm{~min}$ was used. Saliva collection was made from the oral cavity through a microcapillary tube placed between the tongue and the floor of the mouth and transferred to polypropylene microfuge tubes. Saliva collected from four animals was pooled and treated as a single sample. For each treatment group, six samples were collected. Saliva samples were stored at $-70^{\circ} \mathrm{C}$ until further analysis. Total protein content was determined by the method of Lowry et al. (9), using bovine serum albumin as standard.

Influence of T4 treatment on somatic growth and serum iodothyronines. Groups of litter-mate mice treated neonatally with vehicle and $\mathrm{T} 4$ were sacrificed on day 31 by $\mathrm{CO}_{2}$ narcosis. Their body weight and nose-to-rump length were registered. In addition, submandibular glands were removed and weighed. Blood was drawn from the inferior vena cava and used later for serum $\mathrm{T} 4$ and T3 determinations by specific RIAs $(10,11) .{ }^{125}$ I-labeled T4 and T3 were purchased from New England Nuclear Corp., Boston, MA.

Gel electrophoresis. Saliva (180 $\mu \mathrm{g}$ of protein) was mixed with $50 \mu \mathrm{l}$ of electrophoresis cocktail containing SDS $6 \%$, glycerol 
Table 1. Effect of neonatal T4 treatment on somatic growth, serum iodothyronines, and SMG wt*

\begin{tabular}{|c|c|c|c|c|c|c|}
\hline \multirow[b]{2}{*}{ Treatment } & \multirow[b]{2}{*}{ Sex } & \multirow[b]{2}{*}{$\begin{array}{c}\text { Body wt } \\
\text { (g) }\end{array}$} & \multirow[b]{2}{*}{$\begin{array}{l}\text { Body length } \\
(\mathrm{cm})\end{array}$} & \multicolumn{2}{|c|}{ Serum hormones } & \multirow[b]{2}{*}{$\begin{array}{c}\text { SMG wt } \\
\text { (g/100 g body wt) }\end{array}$} \\
\hline & & & & $\begin{array}{c}\mathrm{T} 4 \\
(\mu \mathrm{g} / \mathrm{dl})\end{array}$ & $\begin{array}{c}\mathrm{T} 3 \\
(\mathrm{ng} / \mathrm{dl})\end{array}$ & \\
\hline \multirow[t]{2}{*}{ Vehicle } & $\mathrm{F}$ & 22.34 & 9.26 & 5.09 & 192.00 & 0.703 \\
\hline & & \pm 0.54 & \pm 0.10 & \pm 0.31 & \pm 10.47 & \pm 0.018 \\
\hline \multirow[t]{2}{*}{ Thyroxine } & $\mathrm{F}$ & 15.96 & 8.32 & 4.51 & 174.00 & 0.783 \\
\hline & & \pm 0.78 & \pm 0.18 & \pm 0.32 & \pm 7.97 & \pm 0.025 \\
\hline$p$ value & & $<0.01$ & $<0.01$ & NS & NS & NS \\
\hline \multirow[t]{2}{*}{ Vehicle } & M & 25.51 & 9.62 & 5.26 & 224.83 & 0.734 \\
\hline & & \pm 0.73 & \pm 0.09 & \pm 0.73 & \pm 10.64 & \pm 0.035 \\
\hline \multirow[t]{2}{*}{ Thyroxine } & $\mathrm{M}$ & 18.94 & 8.60 & 5.24 & 218.40 & 0.801 \\
\hline & & \pm 1.46 & \pm 0.27 & \pm 0.29 & \pm 11.66 & \pm 0.075 \\
\hline$p$ value & & $<0.01$ & $<0.01$ & NS & NS & NS \\
\hline
\end{tabular}

* Newborn mouse pups were injected with vehicle (alkaline saline) orT4 $(0.4 \mu \mathrm{g} / \mathrm{g}$ body wt/day) during days $0-6$ and sacrificed on day 31 . The results are given as mean $\pm \mathrm{SEM}$; see text for other details.

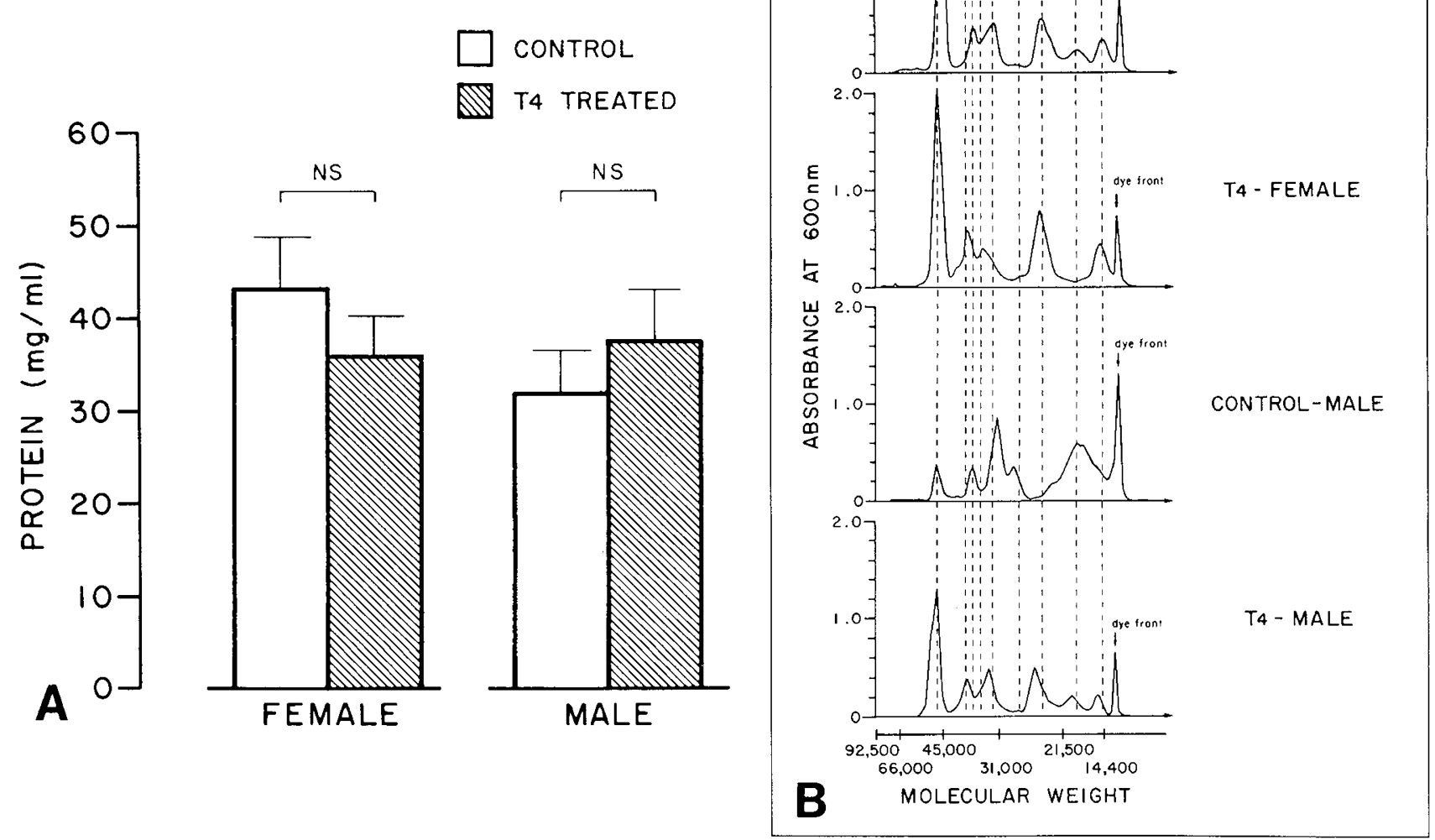

Fig. 1. Effect of T4 treatment on saliva protein secretion. Newborn pups were treated with vehicle or T4 $(0.4 \mu \mathrm{g} / \mathrm{g}$ body weight/day) during days $0-6$. Animals were anaesthetized on day 31 and saliva was collected following epinephrine injection. $A$, saliva protein concentrations as determined by the method of Lowry et al. (9). The values represent mean ( \pm SEM) of six samples in each sex. $B$, analysis of saliva proteins by SDS-gel electrophoresis. For convenience, the protein bands are numbered $1-9$ in the order of decreasing molecular weights. Protein band 1 (50,000 daltons) appeared in both female and male mice. The content was much higher in females than in males. Neonatal T4 treatment increased its concentration slightly in females and markedly in males. Protein band 2 (43,000 daltons) was found only in animals which had been neonatally treated with T4. Conversely, protein band 3 (42,000 daltons) was present only in control female and male mice. Protein band 4 (40,000 daltons) appeared only in saliva of T4-treated female mice. Protein band 5 (37,000 daltons) was found in both female and male control mice. It decreased in T4-treated male mice and was absent in female mice. Protein band 6 (28,000 daltons) was seen only in control male mice. Protein band 7 (27,000 daltons) was present in control and T4-treated female littermates. This band was absent in control male mice but was present in T4-treated male mice. Protein band 8 (20,000 daltons) was found in higher concentration in control males compared to females. This band was absent in T4-treated female mice, but was present in smaller concentrations in hormone-treated male mice. Protein band 9 (15,000 daltons) was present in control female mice, and was absent in control male animals. This band was present in T4-treated female and male mice. 
$6 \%$, Tris- $\mathrm{HCl} 0.2 \mathrm{M}$ (pH 6.8), mercapthoethanol $1 \%$. The samples were placed in a boiling water bath for $5 \mathrm{~min}$ before analysis by SDS-polyacrylamide slab gel electrophoresis ( $2 \mathrm{~mm}$ thickness) using the system of Laemmli (12). A clear separation of salivary protein was achieved using a $10 \%$ running gel $(11.5 \mathrm{~cm}$ in length) and a $4 \%$ stacking gel ( $3 \mathrm{~cm}$ in length). Following electrophoresis at $5 \mathrm{~mA}$ for $20 \mathrm{~h}$, the gel was stained with Coomassie blue and destained. Standard proteins were corun and gels were scanned at $600 \mathrm{~nm}$ in an automatic computing densitometer (Model ACD-18, Gelman Scientific, Inc., Ann Arbor, MI).

$N G F$ and $E G F$ RIA. NGF concentration in saliva was quantified by liquid phase double antibody RIA using $\beta$-NGF antiserum containing two populations of high affinity antibodies with mean affinity constant $5.8 \times 10^{10} \mathrm{liter} / \mathrm{mol}$ (determined by Lineweaver-Burk plot). NGF-RIA buffer contained $0.5 \%$ bovine serum albumin, $0.5 \%$ normal rabbit serum, $0.1 \%$ sodium chloride, and $5 \mathrm{mM}$ EDTA in $0.05 \mathrm{M}$ phosphate buffered saline $\mathrm{pH}$ 7.2. The antiserum was used at a final dilution of $1: 350,000$. NGF-RIA is sensitive enough to detect $16-20 \mathrm{pg} /$ tube. Aliquots of saliva samples were diluted in RIA buffer for determination of NGF by RIA. The incubation and separation were as previously described by Grueter et al. (13).

EGF concentration in saliva was measured by a specific RIA using EGF antiserum containing two populations of high-affinity antibodies with mean affinity constant $1 \times 10^{10}$ liter $/ \mathrm{mol}$ (determined by Lineweaver-Burk plot). The EGF-RIA buffer system, incubation, and separation were as previously described by Hoath et al. (14).

Gel exclusion column chromatography. To assess the molecular size of immunoreactive salivary NGF and EGF, Sephadex G200 fine resin columns $(0.9 \times 56 \mathrm{~cm})$ were equilibrated and developed at $4^{\circ} \mathrm{C}$ with $0.05 \mathrm{M}$ phosphate buffered saline containing $10^{-4} \mathrm{M}$ sodium azide. The columns were calibrated using blue dextran, $\mathrm{Na}^{125} \mathrm{I}(15,000 \mathrm{cpm})$, labeled EGF $(20,000 \mathrm{cpm})$, and unlabelled bovine $\gamma$-globulin and cytochrome $C$ in separate runs. One hundred $\mu \mathrm{l}$ of saliva were applied on each column and eluted by a descending flow $(5.5 \mathrm{ml} / \mathrm{h}) .0 .5 \mathrm{ml}$ fractions were collected in siliconized glass tubes. Fractions were diluted in the RIA buffer and assayed for NGF and EGF by their respective RIA systems.

Statistics. All results were expressed as means \pm SEM. For multiple comparisons, the differences between means were determined by a one-way analysis of variance followed by Student's Newman Keul's test. Significance was assumed at the $5 \%$ level $(p<0.05)$

\section{RESULTS}

Influence of T4 on somatic growth and serum hormones. The effects of T4 treatment on somatic growth, serum T4, T3, and SMG weights in animals sacrificed on day 31 are shown in Table 1. T4 treatment caused growth retardation as indicated by the decreased body weight and body length. Both male and female mice were affected. Mean serum T4 and T3 levels were not significantly different from that of vehicle-treated animals. T4 treatment did not affect the relative SMG weights in both sexes.

Saliva proteins. The amount of protein secreted into saliva, in response to epinephrine stimulation, is shown in Figure $1 \mathrm{~A}$. Total amounts of protein secreted in saliva of both male and female mice on day 31 were not significantly affected by $\mathrm{T} 4$ treatment.

Salivary protein composition was analyzed on a polyacrylamide gel electrophoretic system in the presence of sodium dodecyl sulphate and the gel scanning results are shown in Figure $1 B$. Striking differences in protein profiles for male and female mice saliva were observed. In both sexes, neonatal T4 treatment induced significant alterations. The results are described in the legend for Figure $1 B$.

Changes in salivary NGF and EGF concentrations. The effects of T4 treatment on NGF concentration in saliva of male and female littermate mice are shown in Figure 2 (upper panel). T4 treatment decreased the NGF levels in the saliva of both sexes. The effects of T4 treatment on salivary EGF concentration are shown in Figure 2 (lower panel). T4 treatment also decreased the salivary EGF levels in both sexes.
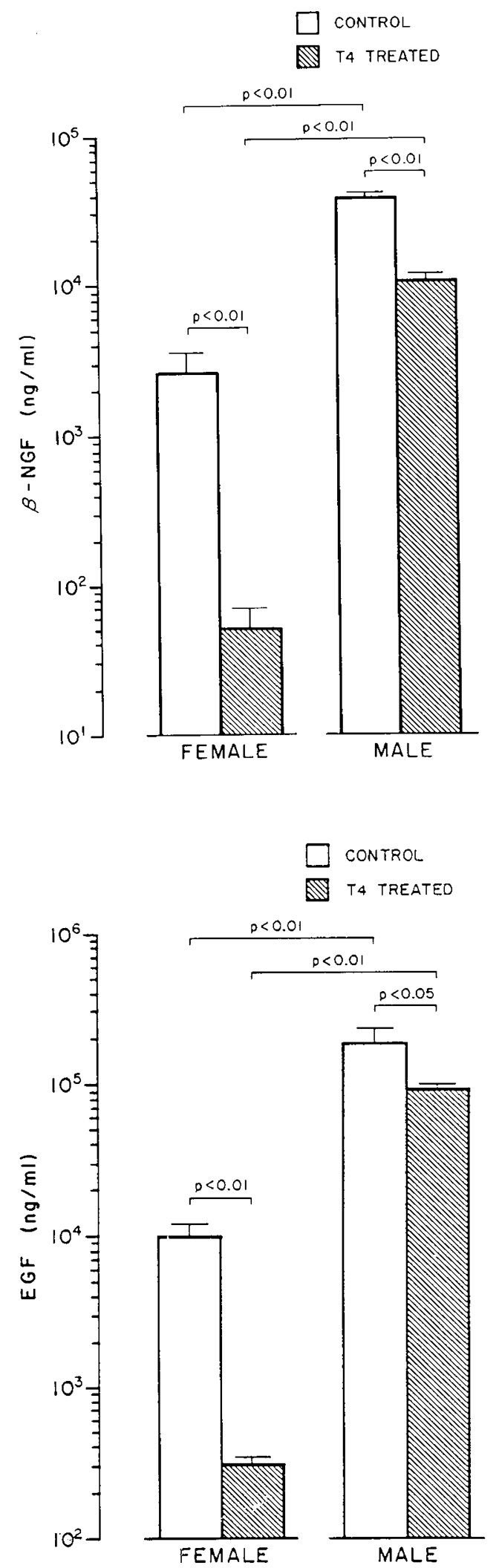

Fig. 2. Effect of T4 treatment of NGF (upper panel) and EGF (lower panel) concentrations in saliva of 31-day-old female and male mice. The values represent the mean $( \pm$ SEM) of six samples in each. See text for other details. 
Molecular properties of salivary NGF and EGF. Sephadex G200 chromatographic profiles of NGF immunoreactivity in saliva of female and male mice are shown in Figure 3. In females (upper panel), NGF immunoreactivity eluted in two distinct peaks. The first peak eluted immediately after the void volume, suggesting this protein is in its high molecular weight state. The elution of this peak was completed before the $\gamma$-globulin position. The second peak began to elute immediately after the $\gamma$-globulin position, suggesting this fraction of NGF is the low molecular weight state. The elution of low molecular weight NGF continued until the end of one column volume is reached, while the elution of this peak in $\mathrm{T} 4$-treated females was completed at a position near cytochrome $\mathrm{C}$

The elution profiles of NGF-immunoreactivity in saliva of control and T4-treated male mice are shown in Figure 3 (lower panel). Although both high and low molecular weight form NGFs were observed in males, the elution of their immunoreactivities were not completed even with two column volumes of the buffer. In control males, the second immunoreactive peak appeared after cytochrome $\mathrm{C}$, while this peak in T4-treated males appeared before the elution of cytochrome $\mathrm{C}$.

The elution pattern of EGF immunoreactivity was similar in saliva of female and male mice (Fig. 4, upper and lower panels). Immunoreactive EGF emerged immediately after $\gamma$-globulin and peaked at a position which corresponded to standard mouse EGF of 6045 molecular weight. The elution pattern suggests that EGF is present in saliva in predominantly low molecular weight form. In both sexes, $\mathrm{T} 4$ treatment did not alter the elution pattern, but the amount was greatly reduced.

\section{DISCUSSION}

The present experiments were undertaken to examine the role of thyroxine on the development of secretory mechanisms specifically for NGF and EGF in mouse saliva. The dose and duration of T4 treatment used in this study were recently shown to abolish the ontogenetic peaks of serum T4 and T3 levels, which occur around day 15 in normal mice (7). The growth responses and serum T4 and T3 levels observed in this study were similar in magnitude to those previously reported for similar age group mice $(6,7)$. On SDS gel electrophoresis, the saliva showed nine major bands. Protein bands 7 and 9 were found in control female mice and were absent in control male animals. Protein bands 1, 2, 4, 7, and 9 were T4 sensitive and their levels were significantly higher in the hormone-treated group. In contrast, the protein bands 5 and 8 were significantly lower in T4treated animals. The results of SDS-PAGE analysis revealed distinct sex differences as well as different T4-induced responses
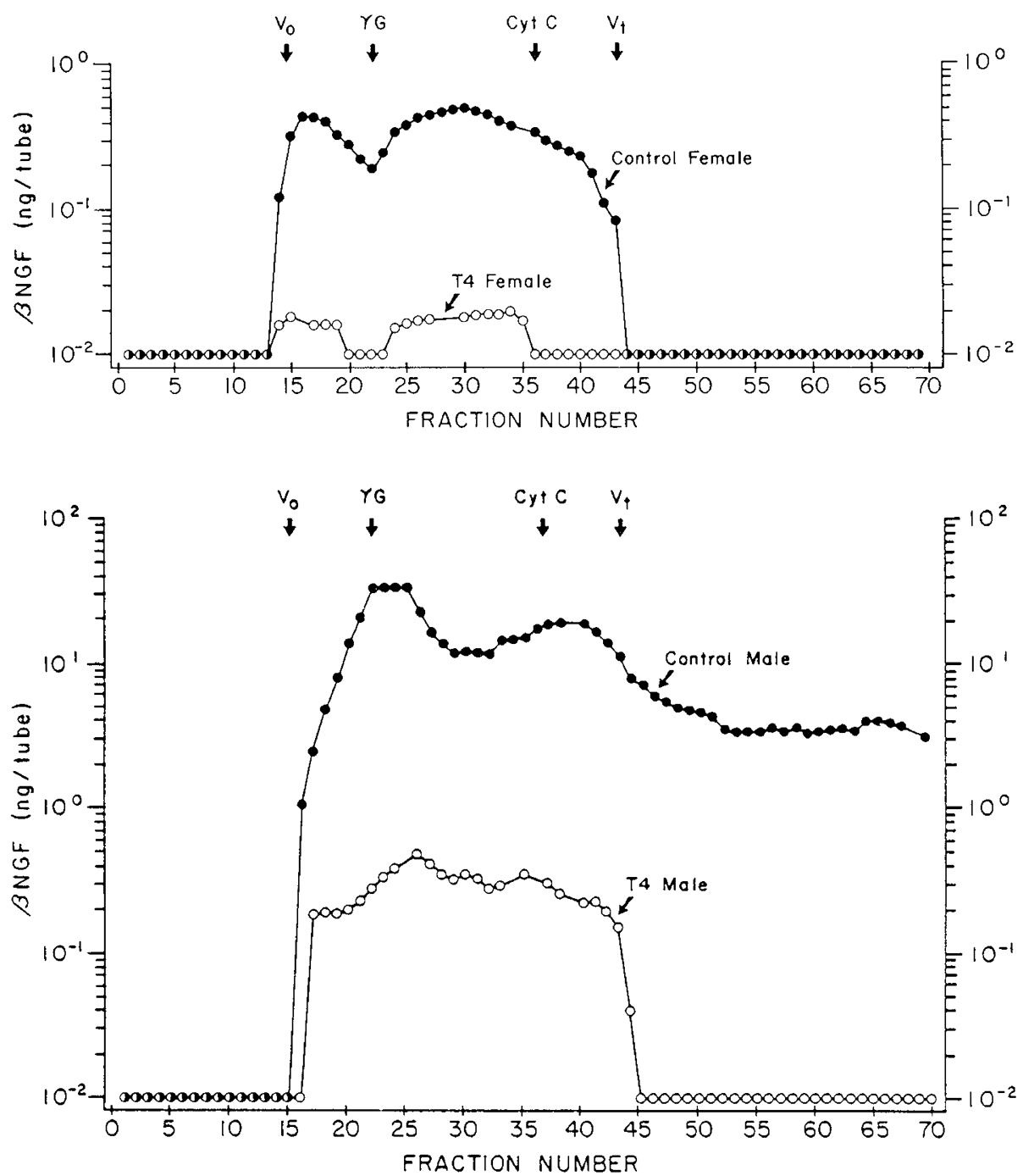

Fig. 3. Chromatogram of $\beta$ NGF immunoreactive material in 31-day-old mouse saliva on Sephadex G-200 fine gel eluted with phosphate-buffered saline. In all cases, $100 \mu \mathrm{l}$ of saliva was loaded on the top of the column and $0.5 \mathrm{ml}$ fractions were collected. Vo, void volume (blue dextran). Vt, total volume $\left(\mathrm{Na}^{125} \mathrm{I}\right)$. Locations of the peaks of bovine $\gamma$-globulin and cytochrome $\mathrm{C}$ are indicated. Column elution profiles for female and male mouse saliva are shown in the upper and lower panels. 

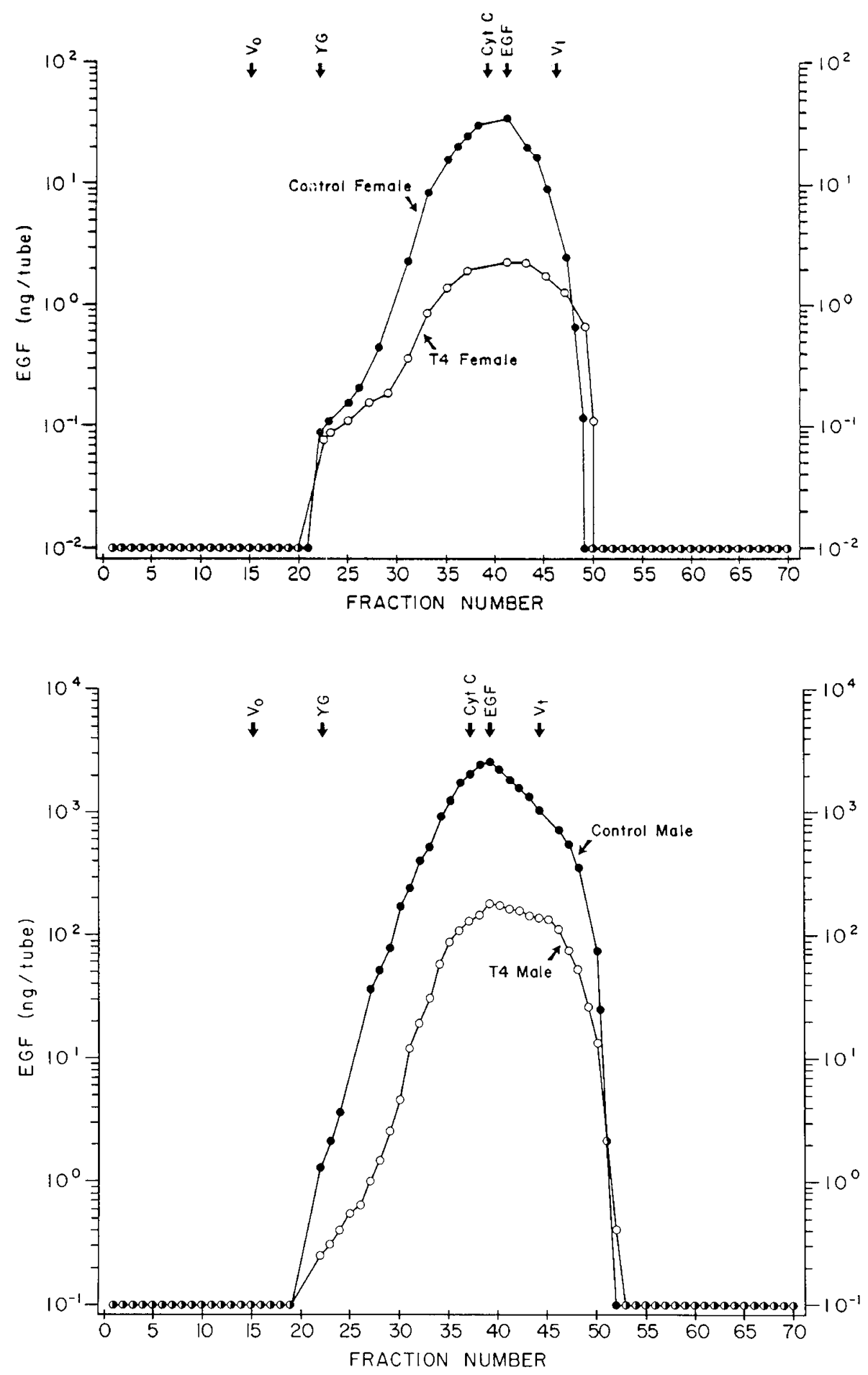

Fig. 4. Chromatogram of EGF immunoreactive material in 31-day-old mouse saliva on Sephadex G-200 fine gel eluted with phosphate-buffered saline. One-hundred $\mu \mathrm{l}$ of saliva were loaded on the column and $0.5 \mathrm{ml}$ fractions were collected. Column elution profiles for female and male mouse saliva are shown in the upper and lower panels. See text for other details.

in the protein constituents secreted in saliva. Neonatal hyperthyroidism did not impair common secretory mechanism since similar changes were not observed in all protein constituents secreted.

The present findings, however, reveal significant sex differences in salivary NGF and EGF concentrations. Both growth factors were secreted in higher concentrations in male compared to female mice. The existence of sex difference in adult mice saliva has previously been reported (15). The higher levels ob- served in males reflect the existence of sexual dimorphism for these growth factors in the submandibular gland $(16,17)$.

More recently, male and female mice that were subjected to T4 treatment with dose and duration as used in this study were found to contain low levels of NGF and EGF in SMG tissues (6, 7). In the present study, marked decreases in salivary NGF and EGF were also observed in T4-treated male and female mice. Further studies are essential to establish whether decreases in salivary NGF and EGF levels represent the decreased glandular 
growth factors level or a defect in the glandular growth factor secretory mechanisms.

In this study, the epinephrine dose (3-6 mg/ $\mathrm{kg}$ body weight), which efficiently provoked salivation in control mice was found to be less effective in T4-treated littermate animals. Hormonetreated animals often required a second dose of epinephrine injection to elicit salivation. Whether the reduced sensitivity to epinephrine represents any alteration in SMG-adrenergic receptor density is presently under investigation. In rat SMG, adrenergic receptors have been reported under the regulation of thyroid hormones (18). However, similar findings have not been reported in mice.

The results of Sephadex column chromatography revealed significant differences in the molecular nature of NGF and EGF secreted into saliva. Although two distinct NGF immunoreactive peaks were observed in male and female mice, the incomplete elution precluded the precise estimation of molecular weights of the secreted NGF. The elution profiles obtained for the high molecular weight form NGF showed significant differences between male and female mice. In males the high molecular weight form NGF peaked immediately after the $\gamma$-globulin fraction, while in females the peak occurred prior to the $\gamma$-globulin fraction. It is not clear whether the observed differences were due to different amounts of NGF or whether other proteins induced alterations in the elution profile. In both sexes, NGF immunoreactivity largely remained in the low molecular weight form. EGF immunoreactivity also largely corresponded to standard EGF of 6045 molecular weight. Interestingly, Burton et al. (19) reported absence of low molecular weight NGF and EGF in saliva of adult male mice. The data presented herein is the first report on the molecular nature of salivary NGF and EGF in mice of younger age. The results of the present study taken together with Burton et al. (19) indicate that the molecular nature of both NGF and EGF secreted into saliva may undergo more developmental changes with increasing age. Further work is necessary to determine what factor(s) regulate the conversion of low molecular weight forms into high molecular weight forms in salivary NGF and EGF secretion. Interestingly, this study indicates that T4 treatment does not alter the molecular nature of NGF and EGF secreted into saliva but the treatment greatly reduces their content.

In summary, neonatal hyperthyroidism causes impairments in the secretions of NGF and EGF into saliva, long after T4 treatment has been discontinued. The mechanism(s) of impairment remain a subject for further investigation.

\section{REFERENCES}

1. Barka T 1980 Biologically active polypeptides in submandibular gland. J Histochem Cytochem 28:836-859

2. Junqueira LC, Fajer A, Rabinovitch M, Frankenthal S 1949 Biochemical and histochemical observations on the sexual dimorphism of mice submaxillary gland. J Cell Comp Physiol 341:129-158

3. Caramia F 1966 Ultrastructure of mouse submaxillary gland. I. Sexual differences. J Ultrastruct Res 16:505-512

4. Kaiho M, Nakamura T, Kumegawa M 1975 Morphological studies on the synthesis of secretory granules in convoluted tubules of mouse submandibular gland. Anal Rec 183:405-420

5. Walker P 1985 Neonatal hyperthyroidism alters submandibular gland epidermal growth factor response to thyroxine in the adult mouse. Can J Physiol Pharmacol 63:1151-1154

6. Lakshmanan J, Beri U, Perheentupa J, Macaso T, Kim H, Fisher DA 1984 Effects of neonatal hyperthyroidism on somatic growth and on submandibular gland and serum epidermal growth factor concentration in one-monthold mice. Pediatr Res 18:331A(abstr)

7. Lakshmanan J, Beri U, Alm J, Macaso T, Kim H, Fisher DA 1984 The influence of neonatal hyperthyroidism on somatic growth serum T4 and submandibular gland (SMG) and serum NGF concentration in one-monthold mice. International Congress of Endocrinology, p1465(abstr)

8. Vreugdenhil AP, deLange GL, Nieuwarmerongen AV, Roukema PA 1980 Morphological changes in the salivary glands upon stimulation by receptorselective agonists. J Biol Buccale 81:73-86

9. Lowry OH, Rosebrough NJ, Farr AL, Randall RJ 1951 Protein measurement with folin phenol reagent. J Biol Chem 193:265-275

10. Chopra IJ 1972 A rapid immunoassay for measurement of thyroxine in unextracted serum. J Clin Endocrin Metabol 34:938-946

11. Chopra IJ, Ho RS, Lam RW 1972 An improved radioimmunoassay of triiodothyronine in serum: its application to clinical and physiological studies. J Lab Clin Metab 80:729-739

12. Laemmli U 1970 Cleavage of structural proteins during assembly of the head of bacteriophage T4. Nature 227:680-686

13. Grueters A, Lakshmanan J, Tarris R, Alm J, Fisher DA 1985 Nerve growth factor in mouse milk during early lactation: lack of dependency on submandibular salivary glands. Pediatr Res 19:934-937

14. Hoath SB, Lakshmanan J, Scott SM, Fisher DA 1983 Effect of thyroid hormones on epidermal growth factor concentration in neonatal mouse skin. Endocrinology 112:308-314

15. Hirata Y, Orth D 1979 Concentrations of epidermal growth factor, nerve growth factor and submandibular gland renin in male and female mouse tissue and fluids. Endocrinology 105:1382-1387

16. Byyny R, Orth D, Cohen S 1972 Radioimmunoassay of epidermal growth factor. Endocrinology 90:1261-1266

17. Caramia F, Angeletti P, Levi-Montalcini R 1962 Experimental analysis of the mouse submaxillary salivary gland in relationship to its nerve growth factor content. Endocrinology 70:915-922

18. Medina JH, Wolfman C, Levi-de-Stein M, Tumilasci O, Houssay AB 1984 Thyroid hormone regulation of adrenergic receptors and beta-adrenergic responsiveness in the rat submandibular gland. Life Sci 35:819-825

19. Burton LE, Wilson WH, Shooter EM 1978 Nerve growth factor in mouse saliva. J Biol Chem 253:7807-7812 